\title{
Clinical significance of heat shock proteins in gastric cancer following hyperthermia stress: Indications for hyperthermic intraperitoneal chemoperfusion therapy
}

\author{
YINUO TU $^{1 *}$, YUNHONG TIAN $^{2 *}$, YINBING WU $^{1}$ and SHUZHONG CUI ${ }^{1}$ \\ ${ }^{1}$ Intracelom Hyperthermic Perfusion Therapy Center, ${ }^{2}$ Department of Radiation Oncology, \\ Affiliated Cancer Hospital \& Institute of Guangzhou Medical University, Guangzhou, Guangdong 510095, P.R. China
}

Received June 14, 2016; Accepted August 1, 2017

DOI: $10.3892 / 01.2018 .8508$

\begin{abstract}
Heat shock proteins (HSPs) are important factors in the response of cancer cells to thermo- and chemotherapy. Transient hyperthermic intraperitoneal chemoperfusion (HIPEC) therapy results in the upregulation of HSP expression, which may compromise the efficacy of additional anticancer treatments. The aim of the present study was to monitor the kinetics of HSP expression in tumor cells and patients with gastric cancer following HIPEC. Thus, in vitro and in vivo experiments were conducted to investigate the expression of two HSP family members, HSP70 and HSP90. Cells from two gastric tumor strains were subjected to HIPEC-mimicking treatment, and HSPs expression was analyzed at specific time points up to $48 \mathrm{~h}$. Serum HSP concentrations were analyzed in patients with gastric cancer who had previously received cytoreductive surgery plus HIPEC treatment. The in vitro experiments indicated a significant elevation of HSP90 expression in gastric adenocarcinoma cells following hyperthermic treatment. However, HSP70 expression increased from $4 \mathrm{~h}$ up to $20 \mathrm{~h}$ post-exposure and decreased to normal levels $36 \mathrm{~h}$ post-exposure. Analysis of HSPs in serum samples collected from 22 patients with gastric cancer confirmed that serum HSP90 and HSP70 levels increased following HIPEC therapy, peaking at $18 \mathrm{~h}$ and returning to normal $24 \mathrm{~h}$ post-exposure. It is therefore advisable to apply the second round of HIPEC or chemotherapy at least $24 \mathrm{~h}$ following the first treatment to minimize any potential thermoresistance and chemoresistance of tumor cells.
\end{abstract}

Correspondence to: Professor Shuzhong Cui, Intracelom Hyperthermic Perfusion Therapy Center, Affiliated Cancer Hospital \& Institute of Guangzhou Medical University, 78 Hengzhigang Road, Guangzhou, Guangdong 510095, P.R. China

E-mail: cuishuzhong@126.com

*Contributed equally

Key words: hyperthermic intraperitoneal chemoperfusion, heat shock protein, thermoresistance, chemoresistance, gastric cancer

\section{Introduction}

Gastric cancer (GC) is the fourth most common type of cancer worldwide, and is particularly prevalent in developing countries (1-3). GC is associated with a high risk of peritoneal carcinomatosis, which occurs in 5-20\% of patients with gastric cancer, and $\sim 50 \%$ of patients with potentially curable advanced gastric cancer die from cancer recurrence in the peritoneum (4-6). Furthermore, peritoneal carcinomatosis is associated with rapid progression, and has been demonstrated to significantly decrease overall survival (7). In previous years, multimodal treatments have emerged for patients with peritoneal carcinomatosis. Cytoreductive surgery (CRS) combined with hyperthermic intraperitoneal chemoperfusion (HIPEC) and systemic chemotherapy have been proposed as beneficial treatment methods (8). This treatment has significantly improved the loco regional control of GC and increased patient survival rates (9-11). Generally, hyperthermia is used to induce temperature-dependent necrosis and protein inactivation (e.g., repair enzymes) as opposed to DNA damage. Furthermore, thermal treatment enhances the cytotoxicity of chemotherapeutic drugs (12).

Transient hyperthermia treatment is able to induce the activation of cellular stress responses, specifically the upregulation of the expression of heat shock proteins (HSPs) (13). HSPs constitute a group of proteins induced by heat shock or cellular stress, which are able to inhibit the misfolding and aggregation of proteins in the cell. HSPs are expressed in multiple types of tumor and promote the survival of cancer cells. They have been reported to be involved in the inhibition of apoptosis in human pancreatic, prostate and gastric cancer cells (14). Furthermore, the synthesis and accumulation of HSPs in tumor cells exposed to hyperthermia are able to protect the cells from further heat-associated cytotoxic events $(15,16)$. HSPs are further responsible for the resistance of cancer cells to radiotherapy and chemotherapy, which makes them a novel target for cancer therapy $(17,18)$.

The upregulation of HSPs is closely associated with a transient resistance of cells towards a subsequent second heat shock, which may protect cells against damage induced by a second round of thermotherapy and chemotherapy. Therefore, elucidating the involvement of HSPs in tumor hyperthermia may 
provide evidence to improve the performance of HIPEC-based treatments. In the present study, the expression patterns of the two most well-studied, stress-inducible members of the HSP family, HSP70 and HSP90, were investigated in gastric cancer cells treated with HIPEC to mimic heating. Furthermore, serum levels of these proteins were analyzed in patients with gastric cancer prior to and following CRS plus HIPEC treatment. The results from the in vitro experiments indicated that the expression of HSP90 was elevated significantly in gastric cancer cells following hyperthermic treatment. However, the expression of HSP70 was elevated from $4 \mathrm{~h}$ up to $20 \mathrm{~h}$ post-exposure and decreased to normal levels at $36 \mathrm{~h}$ post-exposure. Furthermore, analysis of serum samples collected from 22 patients with gastric cancer who received CRS plus HIPEC demonstrated that serum HSP90 and HSP70 levels increased following HIPEC therapy, peaking at $18 \mathrm{~h}$ post-treatment, yet returned to normal levels following $24 \mathrm{~h}$. The present study, which investigated HSP kinetics, aimed to provide evidence to improve the efficacy of therapies that combine the use of hyperthermia and proteasome inhibition, and hence improve the patient outcomes. The results of the present study specifically suggested that conducting a second round of HIPEC or chemotherapy at least $24 \mathrm{~h}$ after the first treatment is optimal to minimize any potential resistance of the tumor cells to the thermal or chemical treatments.

\section{Materials and methods}

Cell culture and hyperthermic treatment. Two strains of human gastric adenocarcinoma cell lines, SGC7901 and AGS cells, were purchased from the American Type Culture Collection (ATCC; Manassas, VA, USA), for use in the present study. Cells were cultured in Dulbecco's modified Eagle's medium (DMEM; Gibco; Thermo Fisher Scientific, Inc., Waltham, MA, USA) supplemented with $10 \%$ fetal bovine serum (FBS; GE Healthcare, Chicago, IL, USA) and incubated at $37^{\circ} \mathrm{C}$ in a humidified atmosphere of $5 \% \mathrm{CO}_{2}$ in air. At $80-90 \%$ confluency, cells were digested with a $0.25 \%$ trypsin solution (Sigma-Aldrich; Merck KGaA, Darmstadt, Germany), and collected by centrifugation at $1,000 \mathrm{x}$ g for $3 \mathrm{~min}$ at $37^{\circ} \mathrm{C}$. Cells were seeded at a density of $5 \times 10^{4}$ cells/well in 6 -well plates in $500 \mu \mathrm{l}$ DMEM with $10 \%$ FBS. Cells were cultured at $37^{\circ} \mathrm{C}$ for $4 \mathrm{~h}$ to allow cells to adhere, followed by cisplatin (3.5 $\mu \mathrm{g} / \mathrm{ml}$; Selleck Chemicals, Houston, TX, USA) treatments for a further $1 \mathrm{~h}$ at $41^{\circ} \mathrm{C}$. The cisplatin-supplemented medium was replaced with DMEM with $10 \%$ FBS and the culture was maintained at $37^{\circ} \mathrm{C}$. Cells were collected prior to and following treatment at multiple specific time points $(0,4,8,12,16,20,24,28,32,36,40,44$ and 48 h). For immunocytochemical (ICC) analysis of HSPs, coverslips were placed in 6-well plates, and cells at a density of $5 \times 10^{4}$ cells/well were seeded into each well. Following $4 \mathrm{~h}$ incubation, the cells were subjected to HIPEC-mimicking hyperthermic treatment as aforementioned. The coverslips were collected and fixed for ICC staining as described below.

Western blot analysis. Cells were lysed in radioimmunoprecipitation assay buffer (Beyotime Institute of Biotechnology, Nanjing, China). Protein concentration was determined using the bicinchoninic acid kit (Beyotime Institute of
Biotechnology). Proteins were mixed with loading buffer and heated at $70^{\circ} \mathrm{C}$ for $10 \mathrm{~min}$ and $30 \mu \mathrm{g} /$ lane was separated by using 7.5\% SDS-PAGE gels. Electrophoresed proteins were transferred onto polyvinylidene fluoride (PVDF) membranes (EMD Millipore, Billerica, MA, USA). The membranes were blocked for $2 \mathrm{~h}$ in $5 \%$ bovine serum albumin (BSA; Beyotime Institute of Biotechnology) at $4^{\circ} \mathrm{C}$ and then incubated overnight at $4^{\circ} \mathrm{C}$ with the mouse monoclonal antibodies against HSP70 (cat. no. sc-2217), HSP90 (cat. no. sc-33755) and GAPDH (cat. no. sc-69778, 1:1,000; Santa Cruz Biotechnology, Inc., Dallas, TX, USA). The blots were then incubated with horseradish peroxidase-conjugated goat anti-mouse secondary antibody (cat. no. sc-2005, 1:1,000; Santa Cruz Biotechnology Inc.). Finally, bands were visualized by enhanced chemiluminescence (Pierce; Thermo Fisher Scientific, Inc.) and LabWorks Image Acquisition and Analysis Software 2 (UVP LLC, Upland, CA, USA).

ICC staining. Coverslips were fixed with $4 \%$ paraformaldehyde for $5 \mathrm{~min}$ at room temperature. Following fixation, coverslips were washed with $0.025 \mathrm{~mol} / \mathrm{l} \mathrm{PBS}$ containing $0.3 \%$ Triton X-100 (PBST) for $10 \mathrm{~min}$. Endogenous peroxidase activity was inactivated by incubating coverslips in $3 \% \mathrm{H}_{2} \mathrm{O}_{2}$ in methanol for $30 \mathrm{~min}$ at room temperature. Following three washes in PBS, antigen retrieval was performed by heating the coverslips in a microwave oven at $121^{\circ} \mathrm{C}$ for $2 \mathrm{~min}$. The coverslips were cooled at room temperature and washed in PBS, and then incubated with $10 \%$ BSA (cat. no. P007, Beyotime Institute of Biotechnology)/PBS Tween-20 for $1 \mathrm{~h}$ at room temperature. Following this, coverslips were incubated with mouse monoclonal primary antibodies against HSP70 (cat. no. sc-2217) and HSP90 (cat. no. sc-33755, 1:100; Santa Cruz Biotechnology, Inc.) for $30 \mathrm{~min}$ at room temperature. Subsequent to washing, the slides were treated with horseradish peroxidase-conjugated goat anti-mouse immunoglobulin G (IgG; cat. no. sc-12358, 1:1,000; Santa Cruz Biotechnology) for $30 \mathrm{~min}$ at room temperature. Following 10 min washing with PBS, sections were incubated with Dako Detection Reagent Envision kit (Agilent Technologies, Inc., Santa Clara, CA, USA) for 5-15 sec at room temperature and were counterstained with hematoxylin for $1 \mathrm{~min}$, followed by dehydration with sequential ethanol washes (75, 80 and 100\%) of $1 \mathrm{~min}$ each at room temperature. Next, the samples were resin-sealed. Finally, the cells were observed under a Nikon Eclipse 50i light microscope (Nikon, Tokyo, Japan).

Reverse transcription-quantitative polymerase chain reaction $(R T-q P C R)$. Total RNA was isolated from cells using TRIzol ${ }^{\mathrm{TM}}$ reagent (Invitrogen; Thermo Fisher Scientific, Inc.), following the manufacturer's protocol. A total of $2 \mu \mathrm{g}$ RNA per sample was reverse transcribed into cDNA using an iScript ${ }^{\mathrm{TM}} \mathrm{cDNA}$ synthesis kit (Bio-Rad Laboratories, Inc., Hercules, CA, USA) according to the manufacturer's protocol. cDNA was used for PCR amplification of HSP70 and HSP90 using an $\mathrm{iQ}^{\mathrm{TM}}$ $\mathrm{SYBR}^{\circledR}$-Green Supermix kit (Bio-Rad Laboratories, Inc.). The qPCRs were repeated a minimum of three times to ensure statistical rigor. Relative quantification of gene expression was performed according to the $2^{-\Delta \Delta \mathrm{Ct}}$ method and normalized to the reference gene GAPDH (19). Primers are listed in Table I. The cycling conditions for qPCR were as follows: Initial 
Table I. Primers used in the present study.

\begin{tabular}{ll}
\hline Primer name & \multicolumn{1}{c}{ Sequence $\left(5^{\prime}-3\right.$ ') } \\
\hline GAPDH forward & TGTTCGTCATGGGTGTGAAC \\
GAPDH reverse & ATGGCATGGACTGTGGTCAT \\
$H S P 90$ forward & ATGGCATGGACTGTGGTCAT \\
$H S P 90$ reverse & GACCCATAGGTTCACCTGTGT \\
$H S P 70$ forward & AGTGATGGATGCAACACAGATT \\
$H S P 70$ reverse & CCAATGTCGTGTCAAATGCAG
\end{tabular}

HSP, heat shock protein.

denaturation at $94^{\circ} \mathrm{C}$ for $2 \mathrm{~min}$, followed by 40 cycles of $30 \mathrm{sec}$ each at $94^{\circ} \mathrm{C}, 30 \mathrm{sec}$ at $58^{\circ} \mathrm{C}$ and $30 \mathrm{sec}$ at $72^{\circ} \mathrm{C}$, with a final extension phase of $72^{\circ} \mathrm{C}$ for $7 \mathrm{~min}$.

Serum collection and analysis. Serum samples were collected from 22 patients with gastric cancer receiving CRS plus HIPEC at the Cancer Center of Guangzhou Medical University (Guangzhou, China) between April 2009 and December 2014. Patients recruited into the study included 12 men and 10 women aged between 22-65 years, with a median age of 49 years. All patients had been diagnosed with gastric adenocarcinoma. A total of 13 patients were diagnosed with poorly or undifferentiated adenocarcinoma, 7 were diagnosed with highly or moderately differentiated adenocarcinoma, and 2 patients with both types of cancer. All of these patients were diagnosed with stage IV gastric cancer. The present study was approved by the Ethics Committee of the Cancer Center of Guangzhou Medical University, and all patients provided written informed consent prior to receiving the treatment.

Surgical procedures. All CRS and HIPEC procedures were performed by a designated team of surgical oncologists, an anesthesiologist and operating room staff, led by chief surgeon Dr Shuzhong Cui at the Cancer Center of Guangzhou Medical University (Guangzhou, China). CRS included several visceral resections of the stomach and small intestine. A parietal peritonectomy was also performed. The abdominal exploration was performed under general anesthesia and hemodynamic monitoring, through a midline xiphoid-pubic incision. Once the abdominal wall was open, detailed evaluation of peritoneal carcinomatosis index was conducted, taking into consideration the size and distribution, according to Sugarbaker (20). The characteristics of ascites were also recorded. Following evaluation, maximal CRS was performed, including the resection of the primary tumor with acceptable margins, any involved adjacent structures, lymphadenectomy, peritoneotomies where peritoneal surfaces were associated with the tumor, according to the peritonectomy procedure developed by Sugarbaker (20). A HIPEC was performed immediately following the CRS procedure. Two inflow drainage tubes were placed in the upper abdomen and two out flow tubes for perfusion were placed in the lower abdomen. A 1-3 liter volume of the heated normal saline was circulated at a rate of $600 \mathrm{ml} / \mathrm{min}$ for $60 \mathrm{~min}$ using the BR-TRG-I Hyperthermic Perfusion Intraperitoneal Treatment system (Baorui Medical Technology, Co., Ltd., Guangzhou, China) at $43^{\circ} \mathrm{C}$ with $20 \mathrm{mg}$ fluorouracil (Selleck Chemicals) and $100 \mathrm{mg}$ cisplatin as the chemotherapeutic agent.

Enzyme-linked immunosorbent assay (ELISA). The serum samples were collected prior to and following HIPEC. HSP70 and HSP90 levels were determined in serum samples using human HSP70 (cat. no. Eh0364) and HSP90 ELISA kits (cat. no. Eh0366) (both from Vipotion Biotechnology Co., Ltd., Guangzhou, China), according to the manufacturer's protocol. Briefly, serum samples were diluted to 1:100 in assay diluent. Diluted samples were added to ELISA assay wells and incubated at $37^{\circ} \mathrm{C}$ for $40 \mathrm{~min}$. Following rinsing with PBST, anti-HSP70 or anti-HSP90 antibodies were added to each well. The plates were incubated for $40 \mathrm{~min}$ at $37^{\circ} \mathrm{C}$ and rinsed with PBST. Plates were incubated with a polyclonal peroxidase-conjugated goat anti-mouse IgG secondary antibody for $15 \mathrm{~min}$ at $37^{\circ} \mathrm{C}$. A volume of 100 enzyme substrate was added to each well, and the assay was incubated for $15 \mathrm{~min}$ at $37^{\circ} \mathrm{C}$. Finally, the plates were measured with a microplate spectrophotometer (VersaMax; Molecular Devices, LLC, Sunnyvale, CA, USA) at an absorbance of $490 \mathrm{~nm}$.

Statistical analysis. Statistical analysis was performed using SPSS statistical software (version 15.0; SPSS, Inc., Chicago, IL, USA). In vitro experiments were representative of three repeats and data are presented as the mean \pm standard deviation (SD). Differences between groups were analyzed using the paired Student's t-test. Statistical differences between groups were assessed using a one-way analysis of variance. Multiple comparisons of the means were performed using the least significance difference test. $\mathrm{P}<0.05$ was considered to indicate a statistically significant difference.

\section{Results}

Expression of HSP70 and HSP9O in tumor cells following hyperthermic treatment. HSP9O expression was significantly elevated in SGC7901 cells at 0, 12, 32 and $48 \mathrm{~h}$ post-hyperthermic treatment compared with pre-treatment levels. However, HSP90 expression was significantly reduced at $16 \mathrm{~h}$ post-treatment compared with that prior to treatment (Fig. 1A). HSP70 expression was significantly upregulated in SGC7901 cells compared with pre-treatment levels, up to $8 \mathrm{~h}$ following treatment, but significantly decreased thereafter at $12 \mathrm{~h}$ post exposure until $48 \mathrm{~h}$ (Fig. 1B). In contrast with the results for SGC7901 cells, the transcription levels as a function of time post-treatment were similar for HSP9O and HSP70 in AGS cells; mRNA expression in each case increased following treatment, peaked at $16-20 \mathrm{~h}(\mathrm{P}<0.05)$, and decreased gradually to pre-treatment levels during the following $24 \mathrm{~h}$ (Fig. $1 \mathrm{C}$ and D). Furthermore, the maximal HSP70 and HSP90 expression levels in gastric cancer cells subjected to hyperthermic treatment were increased 2- to 4-fold compared with the sham group. In addition, the expression of HSP70 increased at the early time points post-exposure, from 4 to $24 \mathrm{~h}$.

Analysis of HSP70 and HSP90 protein levels in tumor cells following hyperthermic treatment. Western blotting and ICC staining were conducted to analyze HSP70 and HSP90 

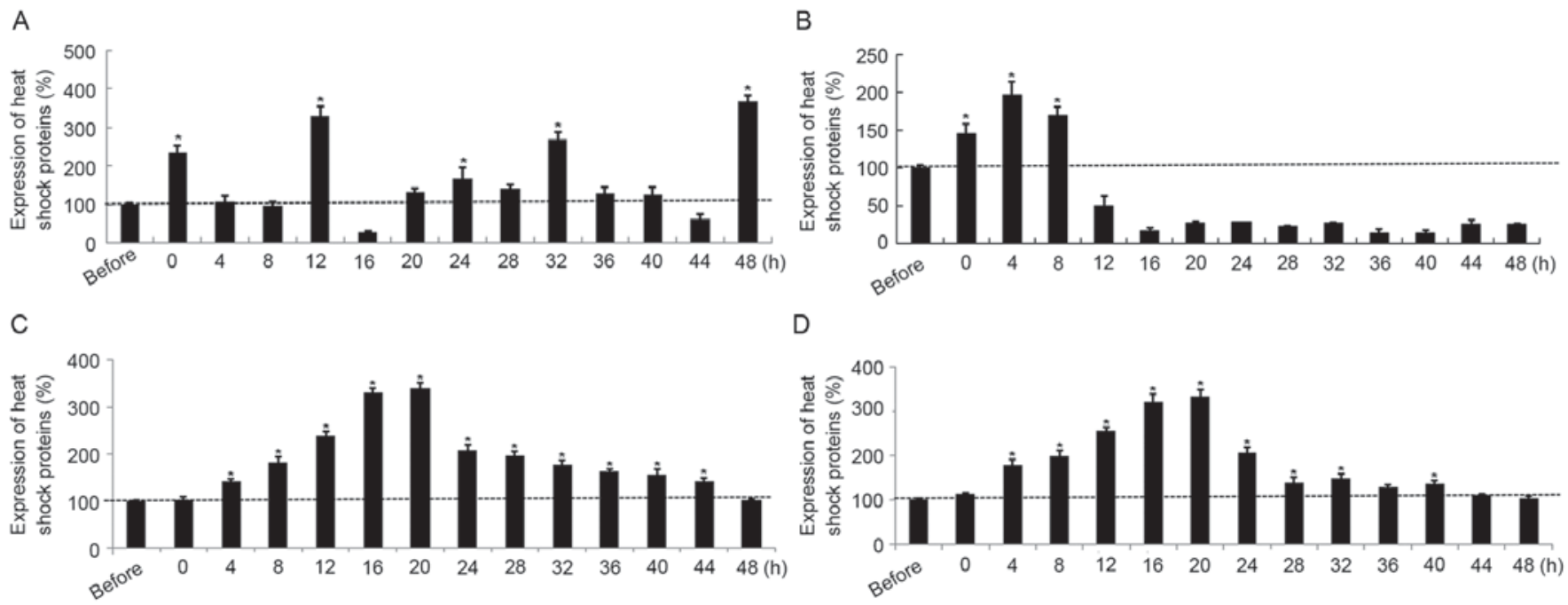

Figure 1. Relative gene expression of (A) HSP90 and of (B) HSP70 in SGC7901 cells following hyperthermic treatment. Relative gene expression of (C) HSP90 and (D) HSP70 in AGS cells following hyperthermic treatment. ${ }^{*} \mathrm{P}<0.05$ vs. prior to treatment. HSP90, heat shock protein 90 ; HSP70, heat shock protein 70.

A

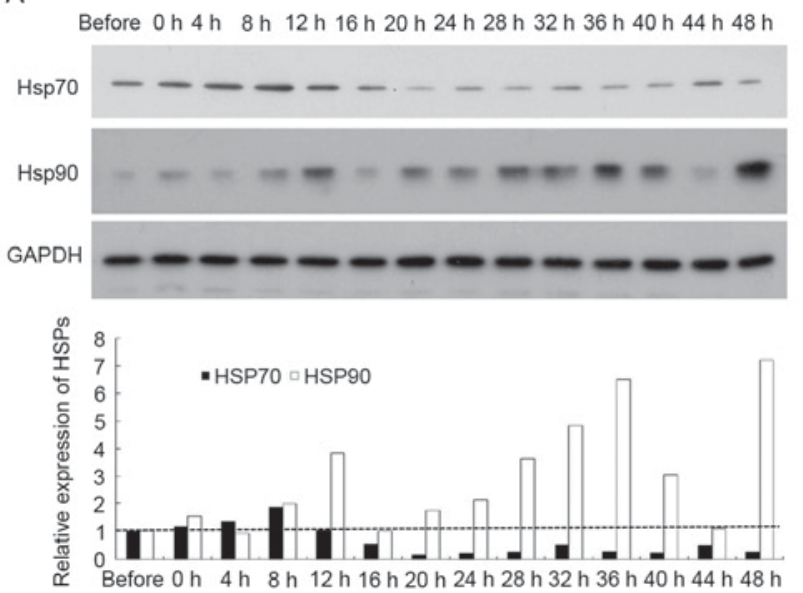
Before $0 \mathrm{~h} 4 \mathrm{~h} 8 \mathrm{~h} 12 \mathrm{~h} 16 \mathrm{~h} 20 \mathrm{~h} 24 \mathrm{~h} 28 \mathrm{~h} 32 \mathrm{~h} 36 \mathrm{~h} 40 \mathrm{~h} 44 \mathrm{~h} 48 \mathrm{~h}$

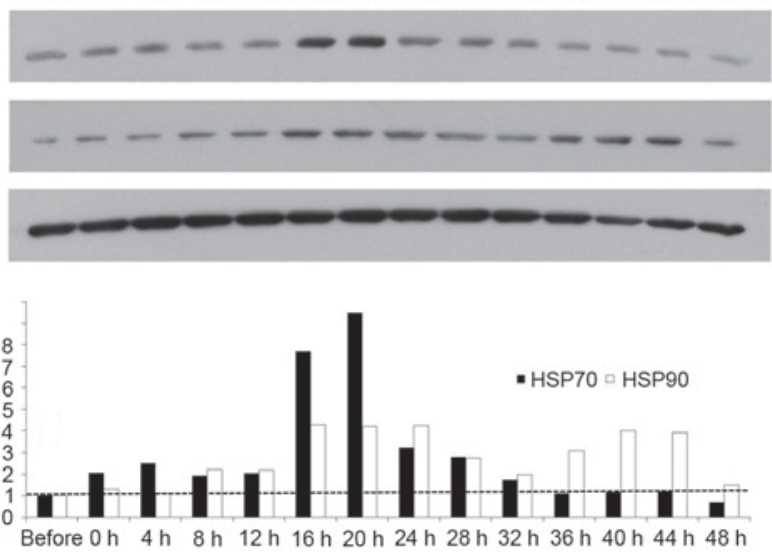

Figure 2. Results of western blotting. HSP90 and HSP70 protein expression were examined in (A) SGC7901 cells and (B) AGS cells, following hyperthermic treatment. $\mathrm{P}<0.05$ vs. prior to treatment. HSP, heat shock protein.

protein levels in SGC7901 and AGS cells following hyperthermic treatment. As presented in Fig. 2A, HSP90 protein levels were significantly increased in SGC7901 cells at 12, 28,32 and $36 \mathrm{~h}$ following hyperthermic treatment, peaking at $48 \mathrm{~h}$. This profile was comparable to that for HSP90 mRNA levels in SGC7901 cells. HSP70 protein levels in SGC7901 cells were similarly comparable to that for HSP70 mRNA levels in SGC7901 cells. In AGS cells, HSP70 protein levels were significantly elevated at 4 up to $20 \mathrm{~h}$ post exposure and decreased to pre-treatment levels $36 \mathrm{~h}$ following treatment (Fig. 2B). HSP90 protein levels significantly increased in AGS cells following hyperthermic treatment, with two high-expression peaks post-treatment, at 16-28 and 36-44 h. The protein levels of HSP70 and HSP90 in gastric cancer cells were determined for hyperthermic stress by ICC staining. The protein expression patterns determined using ICC staining were revealed to be comparable to those described above determined using qPCR and ELISA. A positive HSP70 and HSP90 signal was indicated by a brown stain in fixed cells (Fig. 3). Consistent with the results from western blotting and qPCR, each type of cancer cell demonstrated no detectable staining corresponding to HSPs prior to treatment. However, cells stained positive for HSPs following hyperthermic treatment. Positive staining was mainly observed in the tumor cell nucleus. The expression of HSP90 and HSP70 increased significantly in SGC7901 and AGS cells following hyperthermic treatment. A number of SGC7901 cells were stained positively for HSP70 and HSP90, immediately following treatment for $<8 \mathrm{~h}$. Limited positive staining was observed after $12 \mathrm{~h}$ (Fig. 3A and B). Conversely, HSP70 and HSP90 levels in AGS cells were more apparent between 12 and $24 \mathrm{~h}$ (Fig. 3C and D). Expression of HSP90 and HSP70 increased significantly following hyperthermic treatment and decreased to an almost normal level $36 \mathrm{~h}$ after treatment, although there were differences between SGC7901 and AGS cells.

Serum levels of HSP70 and HSP90 in patients with GC. To dissect the function of HSPs during HIPEC therapy, the expression profile of HSP70 and HSP90 in patients with GC 
A

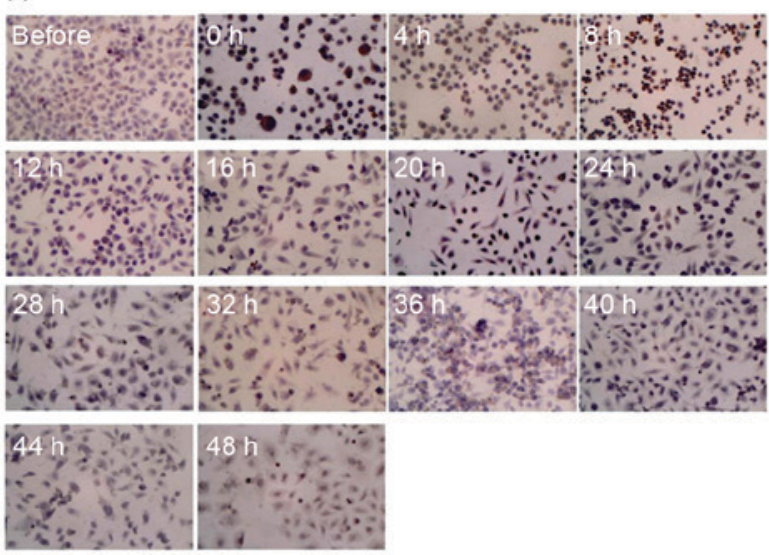

C
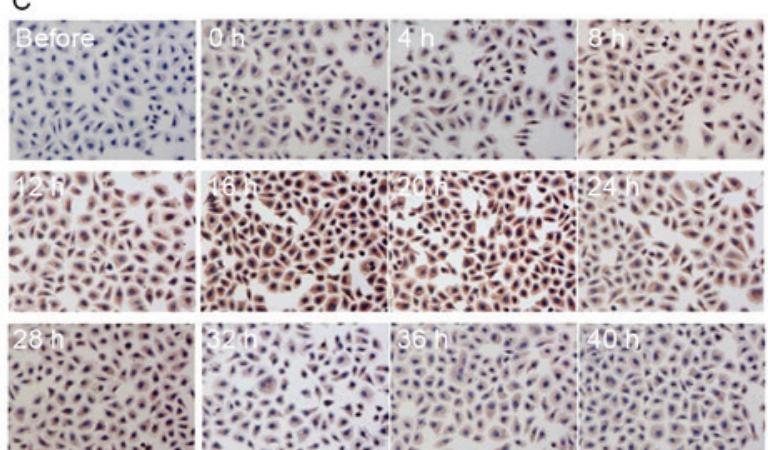

orisos;

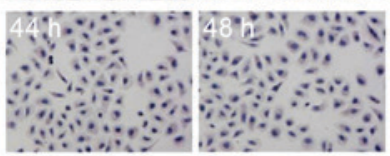

B

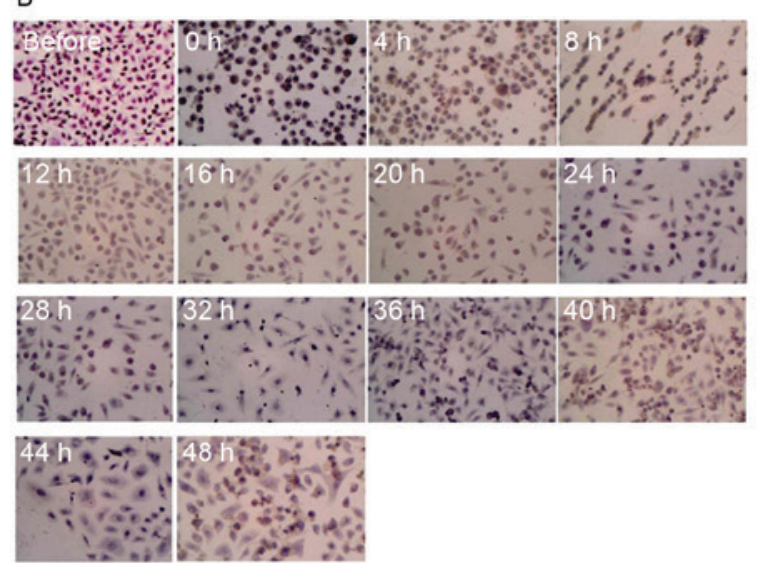

D

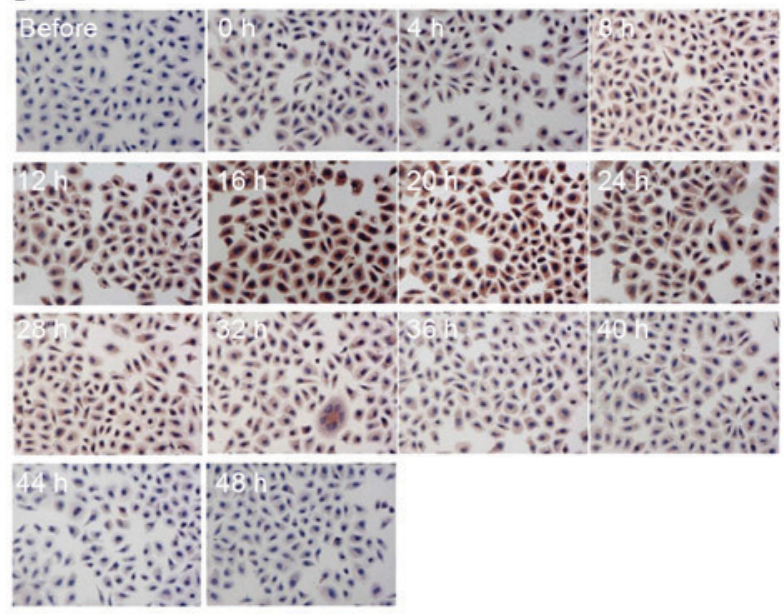

Figure 3. Results of immunocytochemistry. Immunocytochemical staining of (A) HSP70 and (B) HSP90 in SGC7901 cells; and (C) HSP70 and (D) HSP90 in AGS cells following hyperthermic treatment. Positive HSP staining is indicated by brown staining of the cell (magnification, x100). HSP, heat shock protein.
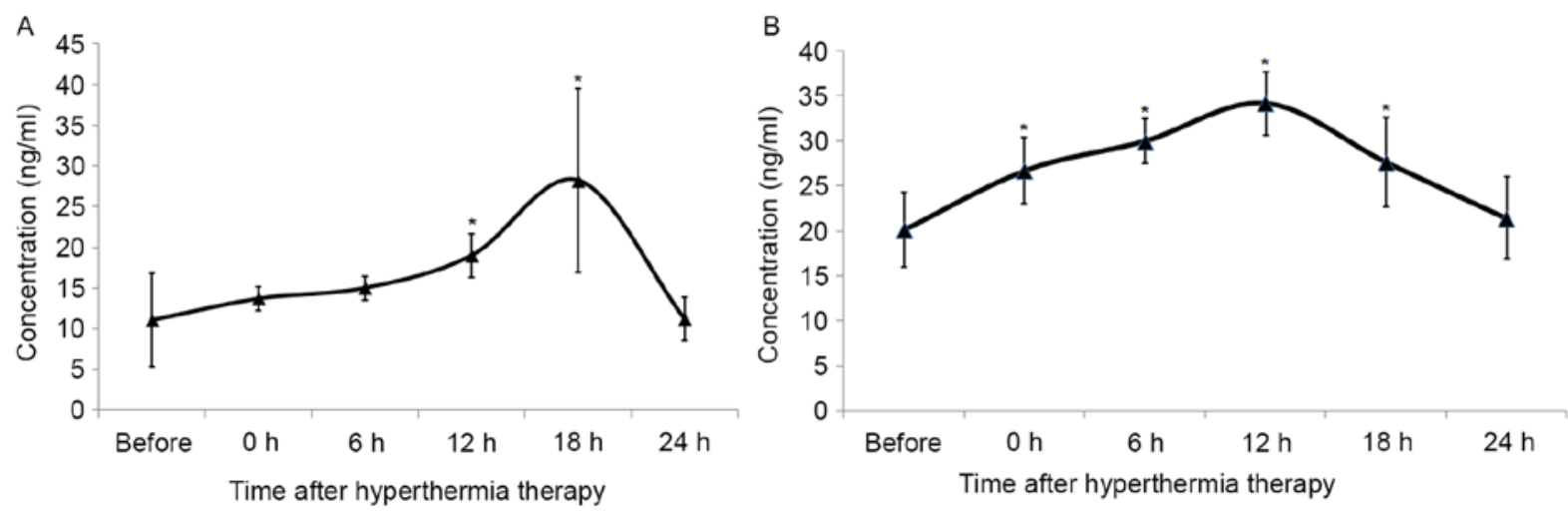

Figure 4. Serum levels of (A) HSP90 and (B) HSP70 within $24 \mathrm{~h}$ of HIPEC therapy. ${ }^{*} \mathrm{P}<0.05$ vs. prior to treatment. HSP, heat shock protein.

exposed to hyperthermia was examined. The serum levels of HSP70 and HSP90 prior to and following HIPEC therapy were analyzed. The concentration of serum HSP90 increased following HIPEC therapy, peaking at $18 \mathrm{~h}$ post-HIPEC therapy, and returned to normal levels by $24 \mathrm{~h}$ post exposure (Fig. 4A). There were no statistical differences observed between concentrations prior to treatment and those at 0,6 and $24 \mathrm{~h}$. The serum concentration of HSP70 increased immediately following treatment, peaking at $12 \mathrm{~h}$, and decreasing to normal levels by $24 \mathrm{~h}$ post-HIPEC therapy (Fig. 4B).

\section{Discussion}

Gastric cancer is one of the most prevalent types of cancer globally, and is particularly common in developing countries (1-3). Despite outstanding advances in medical technology and anticancer therapies, the overall 5-year survival rate of patients with resectable gastric cancer remains poor, due to a high risk of lymphatic spread, hematogenous metastasis and peritoneal metastasis (21). It is widely accepted that direct mechanical contamination, spontaneous tumor rupture, local peritoneal 
trauma and laparoscopic surgery are the major predisposing factors for peritoneal metastasis $(22,23)$. Thus, depletion of peritoneal disseminated cancer cells may improve the outcome for patients with gastric cancer. HIPEC is an effective method for killing disseminated cancer cells in the peritoneal cavity, since hyperthermia is able to enhance the efficacy and penetration of multiple anticancer drugs. Furthermore, CRS plus HIPEC is now considered a standard treatment for several peritoneal carcinomas including colorectal and ovarian cancers $(24,25)$.

Although this multimodal approach improves the locoregional control of gastric cancer and ultimately increases the survival of patients with this disease, HIPEC treatment results in the activation of cellular stress responses; specifically, the expression of HSPs, rendering tumor cells partially thermotolerant and chemotolerant (13). Thus, elucidating the function of HSPs in tumor hyperthermia may further improve the performance of HIPEC-based treatments. In the present study, HSP70 and HSP90 expression patterns were investigated in gastric cancer cells that were subjected to hyperthermic treatments. Furthermore, serum concentrations of HSPs were also analyzed in patients with gastric cancer who had received cytoreductive surgery plus HIPEC treatment. The results from the in vitro experiments indicated that HSP90 was significantly elevated in gastric cancer cells following hyperthermic treatment. However, HSP70 expression increased at 4 up to $20 \mathrm{~h}$ post exposure and decreased to a normal pre-treatment level by $36 \mathrm{~h}$ post exposure. In addition, serum samples collected from 22 patients with gastric cancer who had received CRS plus HIPEC, confirmed that serum HSP70 and HSP90 levels increased and peaked at $18 \mathrm{~h}$, yet returned to normal levels $24 \mathrm{~h}$ post exposure. The present study that investigated HSP kinetics may provide evidence to improve the efficacy of therapies that combine hyperthermic treatments, and hence improve the outcome of patients. Furthermore, these results indicated that decreased HSP70 or HSP90 protein levels may enhance the sensitivity of these cancer cells to CRS plus HIPEC.

HSP90 has been demonstrated to bind and stabilize immature client proteins, a number of which are conformationally unstable proteins involved in signal transduction pathways, important in cell development, growth, and survival. Such proteins include trans-membrane tyrosine kinases, signaling proteins, tumor suppressors and cell-cycle regulators (14). Therefore, HSP90 alters protein activity and participates in cell cycle regulation, thus altering cellular behavior to enhance proliferation (26). HSP90 was expressed in all in vitro experiments in the present study, which is in accordance with its chaperone function. High levels of HSP90 protein are able to contribute to the stabilization and refolding of proteins, impaired by hyperthermic treatment. However, variable levels of HSP90 expression may have a feedback effect on regulating its own expression, in order to inhibit its further accumulation.

In contrast with HSP90, HSP70 has been revealed to promote cell survival by interfering with apoptosis. HSP70 is considered to be a classic apoptotic inhibitor, blocking the intrinsic and extrinsic pathways induced by oxidative damage, chemotherapeutics, radiation and heat-induced stress. Furthermore, HSP70 is able to inhibit p21- and p53-dependent senescence pathways, thereby rescuing cancer cells from apoptosis $(17,27)$. However, HSP70 expression is relatively low in normal cells compared with cancer cells, which suggests that HSP70 expression is crucial for cancer cell survival, but may not be required for non-neoplastic cell survival under normal conditions (28). The in vitro experiments in the present study demonstrated that HSP70 was transiently expressed in cancer cells following hyperthermic treatment. The expression of HSP70 prior to and $24 \mathrm{~h}$ following hyperthermic treatment was relatively low. Similar results were also observed in patients receiving HIPEC treatment, whose serum HSP70 concentration levels peaked $12 \mathrm{~h}$ following treatment and decreased $24 \mathrm{~h}$ post-exposure. The results from the present study suggested an anti-apoptotic function for HSP70 in response to heat-induced stress.

Considering the multiple ways that HSPs aid cell survival, it was anticipated that the HSPs induced by the first round of HIPEC treatment compromised the efficacy of the following HIPEC treatment. HSPs therefore represent promising targets for drugs that aim to increase the effectiveness of cancer thermo- and chemotherapy. Based on the results from the present study, delaying chemotherapy or a second round of a HIPEC treatment for $24 \mathrm{~h}$ post-round one HIPEC treatment is highly recommended. HSPs inhibitors, which have already received considerable attention, are also potential targets with benefits for use in the clinic as adjuncts to HIPEC therapy. Due to the transient high expression of HSPs in cancer cells, HSP vaccines may also be promising adjuncts to HIPEC therapy.

Previous studies have revealed that HSPs are induced by hyperthermia (27). For example, in investigations by Cui et al (29). the expression of HSP70 and HSP90 was significantly upregulated in nasopharyngeal carcinoma cells, which peaked at $4 \mathrm{~h}$ post-heat treatment, followed by a decrease to normal levels at $24 \mathrm{~h}$ post-exposure. Miyagawa et al (30). further demonstrated that the expression of HSP70 and HSP9O were upregulated in melanoma cells, reaching a peak within 4-8 $\mathrm{h}$ following hyperthermia. In addition, it was further demonstrated that inhibition of HSP70 and HSP90 sensitizes melanoma cells to hyperthermia. Furthermore, in patients with peritoneal carcinomatosis from various primary tumors, HSP90 gene expression was upregulated immediately following HIPEC therapy (31). The aforementioned results are consistent with the results of the present study, which demonstrated substantial increases in the serum concentrations of HSP70 and HSP90 from patients immediately following HIPEC treatment. However, HSP70 and HSP90 expression levels in these patients peaked at $18 \mathrm{~h}$, and returned to initial levels $24 \mathrm{~h}$ post-exposure. These inconsistencies with results from the present study may be due to a number of factors. In the present study, cisplatin was added as a chemotherapeutic agent to the perfusate, whilst other previous reports investigated the effects of hyperthermia alone. In addition, in the former two studies, HSP70 and HSP90 expression in cancer cells were measured, whilst serum concentrations were measured in the present study. Expression levels from in vitro experiments may therefore differ from those in patients. Furthermore, the expression of HSP70 and HSP90 increased following HIPEC in a time-dependent manner, which was investigated for the first time in the present study.

In conclusion, the present study is the first to demonstrate that HSP70 and HSP90 are upregulated, then decrease to normal, pre-treatment levels within $24 \mathrm{~h}$ of applying the HIPEC procedure, in tumor cells. It is therefore advisable to apply the second round of HIPEC or chemotherapy at least $24 \mathrm{~h}$ 
following the first treatment to minimize any potential thermoresistance and chemoresistance of tumor cells. Furthermore, the use of co-inhibitors for HSP70 and HSP90 as adjuncts to HIPEC therapy should be considered for future clinical studies. For future studies, having analyzed the effects of the HIPEC procedure on HSPs expression, the further aim is to elucidate the functions of HSPs in HPIEC therapy.

\section{Acknowledgements}

The present study was supported by grants from the $\mathrm{PhD}$ Start-up Funds of Guangzhou Key Medical Discipline Construction Project, Guangzhou Medical College (grant nos. 2015A23, 2014C45 and 2012C69), Guangdong Natural Science Fund (grant no. 2013010016662) and the National Natural Science Foundation of China (grant nos. 81201932, 81502342 and 81372493).

\section{References}

1. Jemal A, Siegel R, Xu J and Ward E: Cancer statistics, 2010. CA Cancer J Clin 60: 277-300, 2010.

2. Bieri U, Moch H, Dehler S, Korol D and Rohrmann S: Changes in autopsy rates among cancer patients and their impact on cancer statistics from a public health point of view: A longitudinal study from 1980 to 2010 with data from Cancer Registry Zurich. Virchows Arch 466: 637-643, 2015.

3. Lozano R, Naghavi M, Foreman K, Lim S, Shibuya K, Aboyans V, Abraham J, Adair T, Aggarwal R, Ahn SY, et al: Global and regional mortality from 235 causes of death for 20 age groups in 1990 and 2010: A systematic analysis for the Global Burden of disease study 2010. Lancet 380: 2095-2128, 2012.

4. Yonemura Y, Endou Y, Sasaki T, Hirano M, Mizumoto A, Matsuda T, Takao N, Ichinose M, Miura M and Li Y: Surgical treatment for peritoneal carcinomatosis from gastric cancer. Eur J Surg Oncol 36: 1131-1138, 2010.

5. Coccolini F, Gheza F, Lotti M, Virzì S, Iusco D, Ghermandi C, Melotti R, Baiocchi G, Giulini SM, Ansaloni L and Catena F: Peritoneal carcinomatosis. World J Gastroenterol 19: 6979-6994, 2013.

6. Yonemura Y, Kawamura T, Bandou E, Tsukiyama G, Endou Y and Miura M: The natural history of free cancer cells in the peritoneal cavity. Recent Results Cancer Res 169: 11-23, 2007.

7. Klaver YL, Lemmens VE, Creemers GJ, Rutten HJ, Nienhuijs SW and de Hingh IH: Population-based survival of patients with peritoneal carcinomatosis from colorectal origin in the era of increasing use of palliative chemotherapy. Ann Oncol 22 2250-2256, 2011.

8. Sugarbaker PH and Ryan DP: Cytoreductive surgery plus hyperthermic perioperative chemotherapy to treat peritoneal metastases from colorectal cancer: Standard of care or an experimental approach? Lancet Oncol 13: e362-e369, 2012.

9. Blackham AU, Swett K, Eng C, Sirintrapun J, Bergman S, Geisinger KR, Votanopoulos K, Stewart JH, Shen P and Levine EA: Perioperative systemic chemotherapy for appendiceal mucinous carcinoma peritonei treated with cytoreductive surgery and hyperthermic intraperitoneal chemotherapy. J Surg Oncol 109: 740-745, 2014.

10. McConnell YJ, Mack LA, Gui X, Carr NJ, Sideris L, Temple WJ, Dubé P, Chandrakumaran K, Moran BJ and Cecil TD: Cytoreductive surgery with hyperthermic intraperitoneal chemotherapy: An emerging treatment option for advanced goblet cell tumors of the appendix. Ann Surg Oncol 21: 1975-1982, 2014.

11. Graziosi L, Cantarella F, Mingrone E, Gunnellini M, Cavazzoni E, Liberati $\mathrm{M}$ and Donini A: Preliminary results of prophylactic HIPEC in patients with locally advanced gastric cancer. Ann Ital Chir 84: 551-556, 2013.

12. Mallory M, Gogineni E, Jones GC, Greer L and Simone CB II: Therapeutic hyperthermia: The old, the new, and the upcoming. Crit Rev Oncol Hematol 97: 56-64, 2016.
13. Kepenekian V, Aloy MT, Magné N, Passot G, Armandy E, Decullier E, Sayag-Beaujard A, Gilly FN, Glehen O and Rodriguez-Lafrasse C: Impact of hyperthermic intraperitoneal chemotherapy on Hsp27 protein expression in serum of patients with peritoneal carcinomatosis. Cell Stress Chaperones 18: 623-630, 2013

14. Lianos GD, Alexiou GA, Mangano A, Mangano A, Rausei S, Boni L, Dionigi G and Roukos DH: The role of heat shock proteins in cancer. Cancer Lett 360: 114-118, 2015.

15. Ischia J and So AI: The role of heat shock proteins in bladder cancer. Nat Rev Urol 10: 386-395, 2013.

16. Zorzi E and Bonvini P: Inducible hsp70 in the regulation of cancer cell survival: Analysis of chaperone induction, expression and activity. Cancers (Basel) 3: 3921-3956, 2011.

17. Wang X, Chen M, Zhou J and Zhang X: HSP27, 70 and 90 , anti-apoptotic proteins, in clinical cancer therapy (Review). Int J Oncol 45: 18-30, 2014.

18. Schilling D, Bayer C, Li W, Molls M, Vaupel P and Multhoff G: Radiosensitization of normoxic and hypoxic h1339 lung tumor cells by heat shock protein 90 inhibition is independent of hypoxia inducible factor-1 $\alpha$. PLoS One 7: e31110, 2012.

19. Livak KJ and Schmittgen TD: Analysis of relative gene expression data using real-time quantitative PCR and the 2(-Delta Delta C(T)) method. Methods 25: 402-408, 2001.

20. Sugarbaker PH: Cytoreductive surgery and perioperative intraperitoneal chemotherapy as a curative approach to pseudomyxoma peritonei syndrome. Tumori 87: S3-S5, 2001.

21. Fang C, Hua J, Li J, Zhen J, Wang F, Zhao Q, Shuang J and Du J: Comparison of long-term results between laparoscopy-assisted gastrectomy and open gastrectomy with D2 lymphadenectomy for advanced gastric cancer. Am J Surg 208: 391-396, 2014.

22. Kow AW, Kwon CH, Song S, Shin M, Kim JM and Joh JW: Risk factors of peritoneal recurrence and outcome of resected peritoneal recurrence after liver resection in hepatocellular carcinoma: Review of 1222 cases of hepatectomy in a tertiary institution. Ann Surg Oncol 19: 2246-2255, 2012.

23. Rodriguez EF, Monaco SE, Khalbuss W, Austin RM and Pantanowitz L: Abdominopelvic washings: A comprehensive review. Cytojournal 10: 7, 2013.

24. Königsrainer I, Horvath P, Struller F, Forkl V, Königsrainer A and Beckert S: Risk factors for recurrence following complete cytoreductive surgery and HIPEC in colorectal cancer-derived peritoneal surface malignancies. Langenbecks Arch Surg 398: 745-749, 2013.

25. Cashin PH, Graf W, Nygren P and Mahteme H: Cytoreductive surgery and intraperitoneal chemotherapy for colorectal peritoneal carcinomatosis: Prognosis and treatment of recurrences in a cohort study. Eur J Surg Oncol 38: 509-515, 2012.

26. Sevin M, Girodon F, Garrido C and de Thonel A: HSP90 and HSP70: Implication in inflammation processes and therapeutic approaches for myeloproliferative neoplasms. Mediators Inflamm 2015: 970242, 2015.

27. Jego G, Hazoumé A, Seigneuric R and Garrido C: Targeting heat shock proteins in cancer. Cancer Lett 332: 275-285, 2013.

28. Sherman MY and Gabai VL: Hsp70 in cancer: Back to the future. Oncogene 34: 4153-4161, 2015.

29. Cui XB, Yu ZY, Wang W, Zheng YQ, Liu W and Li LX: Co-inhibition of HSP70/HSP90 synergistically sensitizes nasopharyngeal carcinoma cells to thermotherapy. Integr Cancer Ther 11: 61-67, 2012.

30. Miyagawa T, Saito H, Minamiya Y, Mitobe K, Takashima S, Takahashi N, Ito A, Imai K, Motoyama S and Ogawa J: Inhibition of Hsp90 and 70 sensitizes melanoma cells to hyperthermia using ferromagnetic particles with a low Curie temperature. Int J Clin Oncol 19: 722-730, 2014.

31. Pelz JO, Vetterlein M, Grimmig T, Kerscher AG, Moll E, Lazariotou M, Matthes N, Faber M, Germer CT, Waaga-Gasser AM and Gasser M: Hyperthermic intraperitoneal chemotherapy in patients with peritoneal carcinomatosis: Role of heat shock proteins and dissecting effects of hyperthermia. Ann Surg Oncol 20: 1105-1113, 2013. 